\title{
How to select publications on occupational health: the usefulness of Medline and the impact factor
}

\author{
J F Gehanno, B Thirion
}

\begin{abstract}
Objectives-Publications in the field of occupational health appear in various journals, including those of other medical specialties. This complicates the follow up of literature for specialists in this field. On the basis of Medline and the impact factor, this diversity was assessed, and a cost effective method for selecting the most pertinent journals in the practice of occupational health was proposed.

Methods-A Medline search identified all the articles published in 1998 with occupational diseases or occupational exposures as the main topic. These articles were classified based on the journals in which they appeared. The journals were then compared according to their subject area, the number of articles that were published in the fields studied, and their impact factor.

Results-The search retrieved 2247 articles, published in $\mathbf{5 7 7}$ different journals in 1998. Each journal published between one and $\mathbf{1 0 5}$ articles during this period (mean 3.89 ). However, only $1.4 \%$ of the journals accounted for more than $25 \%$ of the total articles published. More than half of the articles were published in journals dealing with general practice or medical specialties other than occupational health. Only $66 \%$ of retrieved journals had an impact factor, and more than $80 \%$ of the articles were published in journals with an impact factor $<2$.

Conclusion-Simply following up occupational health journals is not sufficient to meet the requirements of the occupational health professional. Moreover, the use of the impact factor cannot be considered as a reliable research tool to assess follow up. Two lists of eight and 38 journals were thus set up. They permit a literature coverage of $27 \%$ and $52 \%$ respectively in the specific fields studied, and this seems to be the optimal compromise between time and literature covered. Lastly, practical procedures are suggested to follow up literature and obtain abstracts from selected journals on the internet.

(Occup Environ Med 2000;57:706-709)
\end{abstract}

Keywords: occupational health; bibliographic databases; impact factor; Medline

Occupational health covers many basic and clinical research fields. The articles dealing with related topics are therefore published in a wide range of journals, and not only in occupa- tional health journals. Specialists in occupational health, as well as specialised librarians, thus confront a problem when trying to follow up occupational health literature. The same problem is faced by research workers in occupational health when they try to choose the most appropriate vehicles to obtain the wider audience or the maximum impact on people working in the same field of research. Therefore, what should be the criteria of choice for these professionals? The journal's subject area can be valuable, but this criteria is often insufficient. ${ }^{1}$ The impact factor is a bibliometric tool which assesses the coverage of a journal, ${ }^{2}$ but it may be subject to some bias. With Medline, we searched all the articles published in 1998, and in which the main topic was either occupational diseases or occupational exposures. The purpose was to compare the methods used to assess the usefulness of journals in the specific field of occupational health, and to develop the optimal strategy to follow up occupational health publications.

\section{Methods}

In May 1999, Medline was searched for the articles published in 1998 dealing with occupational diseases or occupational exposures. Medline is the on line and CD-ROM equivalent of Index Medicus, and is produced by the National Library of Medicine in the USA (NLM, Bethesda, MD, USA). It contains more than eight million records from over 3500 biomedical national and international journals, covering the period 1966 to the present, and increases by 324000 records per year. The medical subject headings $(\mathrm{MeSH})$ terms occupational diseases and occupational exposure were used and explode and focus functions were applied. ${ }^{3}$ All the articles retrieved were classified by the journals in which they were published, and the journals were compared on the basis of their subject area, the number of articles they published in the field studied, and on their impact factor.

Four subject areas (occupational health, toxicology, environmental health, other specialty, or general practice) were defined. This classification scheme was more precise that the one adopted by the Institute for Scientific Information (ISI) (Philadelphia, USA), in which journals dealing with occupational health, environmental health, and public sciences are grouped into a chapter entitled "public, environmental, and occupational health". We classified journals according to their principal fields of interest. For example, Occupational Medicine, the American fournal of Industrial Medicine, or Medicina del Lavoro were 
Table 1 Classification of journals according to the number of articles published in 1998

\begin{tabular}{lcc}
\hline $\begin{array}{l}\text { Articles published } \\
\text { by each journal } \\
(n)\end{array}$ & $\begin{array}{l}\text { fournals } \\
\text { concerned } \\
(n(\%))\end{array}$ & $\begin{array}{l}\text { Total articles published in } \\
\text { the journals in each } \\
\text { category }(n(\%))\end{array}$ \\
\hline 1 & $333(57.7)$ & $335(15)$ \\
$2-10$ & $210(36.4)$ & $774(34)$ \\
$11-20$ & $18(3.1)$ & $274(12)$ \\
$21-30$ & $4(0.7)$ & $101(4)$ \\
$31-40$ & $2(0.4)$ & $63(3)$ \\
$41-50$ & $2(0.4)$ & $85(4)$ \\
$51-60$ & $0(0)$ & $0(0)$ \\
$61-70$ & $4(0.7)$ & $255(11)$ \\
$71-80$ & $1(0.2)$ & $71(3)$ \\
$81-90$ & $1(0.2)$ & $83(4)$ \\
$91-100$ & $0(0)$ & $0(0)$ \\
$101-110$ & $2(0.4)$ & $206(9)$ \\
Total & $577(100)$ & $2247(100)$ \\
\hline
\end{tabular}

classified in occupational health journals, Toxicology Letters or Critical Reviews in Toxicology were classified in toxicology journals, and Environmental Health Perspectives or Chemosphere in environmental health journals. In the analysis, we grouped journals dealing with occupational or environmental health and toxicology because those topics are closely related and because the distinction bewteen occupational health journals and environmental health journals tends to be more and more difficult to assess, as shown by the transformation in 1994 of the British fournal of Industrial Medicine into Occupational and Environmental Medicine.

The citation rate is calculated on the basis of the database science citation index (SCI), produced by ISI, which contains up to 13 million records and 150 million scientific citations, since 1964, from more than 4900 journals in many different research fields. ${ }^{4}$ The citations are represented by the reference lists of articles from many of the world's scientific journals. The references are rearranged in the database to show how many times each publication has been cited within a certain period, and by whom. The impact factor is defined as the recorded number of citations within a certain year divided by the number of items published in the journal during the two preceding years. ${ }^{4}$ In this study, the impact factors published in 1998 were used.

\section{Results}

Out of 2247 articles retrieved, a total of 1269 were concerned only with occupational diseases, 745 only with occupational exposure, and 233 with both. The articles appeared in 577 different journals. Most of them were English language journals, but some were in German ( $n=184)$, in Russian $(n=111)$, in Italian $(n=72)$, in Spanish $(n=47)$, in French $(n=42)$, in Polish $(n=31)$, in Japanese $(n=15)$,

Table 2 Number of articles published by group of journals, according to their main subject area

\begin{tabular}{lccc}
\hline & Articles $(n(\%))$ & fournals $(n(\%))$ & $\begin{array}{l}\text { Total impact factors of } \\
\text { journals }\end{array}$ \\
\hline Occupational health & $844(37.6)$ & $26(4.5)$ & 11.382 \\
Toxicology & $40(1.8)$ & $14(2.4)$ & 13.018 \\
Environmental health & $92(4.1)$ & $14(2.4)$ & 13.291 \\
Other & $1271(56.6)$ & $523(90.6)$ & 566.027 \\
Total & $2247(100)$ & $577(100)$ & 603.718 \\
\hline
\end{tabular}

Table 3 Classification of journals according to their impact factor

\begin{tabular}{lcc}
\hline Impact factor & $\begin{array}{c}\text { fournals } \\
(n(\%))\end{array}$ & $\begin{array}{c}\text { Articles published in } \\
\text { these journals }(n(\%))\end{array}$ \\
\hline$>20$ & $2(0.3)$ & $6(0.3)$ \\
$10-19$ & $5(0.9)$ & $12(0.5)$ \\
$5-9$ & $10(1.7)$ & $18(0.8)$ \\
$4-4.999$ & $9(1.6)$ & $37(1.6)$ \\
$3-3.999$ & $19(3.3)$ & $68(3.0)$ \\
$2-2.999$ & $44(7.6)$ & $147(6.5)$ \\
$1-1.999$ & $83(14.4)$ & $699(31.1)$ \\
$<1$ & $149(25.8)$ & $463(20.6)$ \\
Not indexed in SCI & $256(44.4)$ & $797(35.5)$ \\
Total & $577(100.0)$ & $2247(100.0)$ \\
\hline
\end{tabular}

$\mathrm{SCI}=$ science citation index.

in Ukrainian $(n=15)$, in Portuguese $(n=9)$, in Dutch $(n=4)$, in Serbo-croat $(n=4)$, or in Slovenian $(n=2)$.

Table 1 shows the journals classified according to the number of articles they published in 1998. Each journal published between one and 105 articles during this period (mean 3.89) but $1.4 \%$ of the journals published more than a quarter of the total articles and $94.2 \%$ of the journals accounted for only one half of the total articles published.

Table 2 presents the number of articles published by journals, classified according to their main subject area (occupational health, toxicology, environmental health, other specialty or general practice). Of the articles, $43.5 \%$ appeared in journals with the subject area occupational health, or closely related - that is, toxicology or environmental health. These journals represented $9.3 \%$ of the total number of journals. Nevertheless, more than half of the articles were published in journals with subject areas general practice or other medical or scientific specialties.

Tables 2 and 3 present the number of articles published in journals classified according to their impact factor. Only two thirds $(65.6 \%)$ of the journals retrieved were indexed in the SCI, and thus had an impact factor. Furthermore, among the 54 journals with the subject area occupational health (or related to it), the impact factor was calculated by the ISI for only $25(46.3 \%)$, and was <4.824 (mean 1.300 ).

Last but not least, although some articles appeared in journals with a high impact factor (Nature Medicine, Lancet, or New England Fournal of Medicine), more than $80 \%$ of the articles were published in journals with an impact factor $<2$.

\section{Discussion}

Medline was used to identify all the information sources in occupational health, because this database contains information on all the fields relevant in occupational health, is available worldwide, and was adopted by many if not all medical libraries. Furthermore, it can be searched free of charge with the internet (through PubMed).

Nevertheless, Medline indexes mainly English language journals, is dominated by American publications, and, as the other biomedical bibliographic databases when used alone, is not exhaustive in the field of occupational health. ${ }^{1}$ Despite these shortcomings, Medline includes 
Table 4 Periodicals classified in categories according to the number of articles they published in the fields studied in 1998

\begin{tabular}{|c|c|c|c|c|c|}
\hline >100 Articles in 1998 & $\begin{array}{l}\text { Impact } \\
\text { factor }\end{array}$ & 50-99 Articles in 1998 & $\begin{array}{l}\text { Impact } \\
\text { factor }\end{array}$ & 10-49 Articles in 1998 & $\begin{array}{l}\text { Impact } \\
\text { factor }\end{array}$ \\
\hline $\begin{array}{l}\text { Am } \mathcal{F} \text { Ind Med } \\
\text { Occup Environ Med }\end{array}$ & $\begin{array}{l}1.280 \\
1.681\end{array}$ & $\begin{array}{l}\text { Contact Dermatitis } \\
\text { Int Arch Occup Environ Health } \\
\text { f Occup Environ Med } \\
\text { Scand } \mathcal{F} \text { Work Environ Health } \\
\text { Med Tr Prom Ekol } \\
\text { Occup Med (Lond) }\end{array}$ & $\begin{array}{l}1.130 \\
1.252 \\
1.671 \\
1.708 \\
- \\
0.540\end{array}$ & $\begin{array}{l}\text { Med Lav } \\
\text { Am Ind Hyg Assoc } \mathcal{F} \\
\text { Ann Occup Hyg } \\
\text { Lik Sprava } \\
\text { Int } \mathcal{f} \text { Occup Environ Health } \\
\text { Occup Health Saf } \\
\text { Ind Health } \\
\text { Med Pr } \\
\text { Mutat Res } \\
\text { Arch Environ Health } \\
\text { Am f Epidemiol } \\
\text { Am } \mathcal{F} \text { Respir Crit Care Med } \\
\text { Int } \mathcal{f} \text { Occup Med Environ Health } \\
\text { Allergy } \\
\text { Health Phys } \\
\text { Eur Respir } \mathcal{F} \\
\text { Pneumologie } \\
\text { Environ Health Perspect Suppl } \\
\mathcal{F} \text { Allergy Clin Immunol } \\
\text { American Association of Occupational } \\
\text { Health Nurses fournal } \\
\text { G Ital Med Lav Ergon } \\
\text { Ergonomics } \\
\text { Clin Exp Allergy } \\
\text { Environ Health Perspect* } \\
\text { Spine } \\
\text { Ugeskr Laeger } \\
\text { Cancer Epidemiol Biomarkers Prev } \\
\text { Environ Res } \\
\text { Gig Sanit } \\
\text { S Afr Med } \mathcal{F}\end{array}$ & $\begin{array}{l}- \\
0.766 \\
0.818 \\
- \\
- \\
- \\
- \\
1.754 \\
1.226 \\
3.773 \\
4.705 \\
- \\
2.015 \\
0.827 \\
1.923 \\
- \\
2.119 \\
3.769 \\
- \\
- \\
0.749 \\
2.559 \\
2.119 \\
1.568 \\
- \\
2.932 \\
1.552 \\
- \\
0.726\end{array}$ \\
\hline
\end{tabular}

${ }^{\star}$ Environmental Health Perspectives and Environmental Health Perspectives Supplement are two distinct journals, with different subscription procedures.

a highly efficient hierarchical thesaurus and provides the explode and focus function. The focus function allows the search to be confined to the articles in which the topics studied are considered to be the main topics. The use of these two functions ensures that the search performed in this study was reliable in the two fields studied. Despite the fact that the database is not exhaustive, that the topics studied represent only a part of all the topics of occupational health, and that the focus function was applied, the number of retrieved articles shows the amount of literature which exists relating to occupational health. Furthermore, the number of journals involved confirms the diversity of sources, which may present problems to the occupational health specialist when trying to assess the most relevant journals to follow up.

It would seem advisable to select the most prominent journals in occupational health (Occupational and Environmental Medicine, American Fournal of Industrial Medicine, International Archives of Occupational and Environmental Health, Fournal of Occupational and Environmental Medicine, Scandinavian fournal of Work and Environmental Health, Occupational Medicine (London), Annals of Occupational Hygiene, and International fournal of Occupational and Environmental Health). Nevertheless, these journals have published only 529 articles in 1998 in the fields studied - that is, $23.5 \%$ of the total articles. Moreover, following up all the journals with the subject area occupational health would lead to a follow up of more than 40 journals, but would still cover $<50 \%$ of the relevant publications. Therefore, following up only occupational health journals is important but insufficient to cover the literature in occu- pational health; another method for selecting journals is still required.

An approach based on the impact factor of the journals retrieved in the search could be more useful. The impact factor of a scientific journal is the mean citation rate of all the articles contained in the journal and is widely considered as a quality ranking for journals. This is the only tool available but it has numerous shortcomings. Some are not specific to occupational health and have been reviewed by Seglen. ${ }^{4}$ Briefly, the SCI covers about 4900 journals, mainly in the English language, compared with an estimated world total of $126000 .^{5}$ Secondly, the impact factor is calculated in a way that favours review articles as they generally receive a greater number of citations than ordinary articles. Thirdly, the journal impact factor is not representative of the citation rate of individual articles in the journal. Seglen ${ }^{6}$ has shown that the most cited half of the articles are cited, on average, 10 times as often as the least cited half. Thus, the impact factor cannot readily be applied to assess the citation rates of individual articles in the journal nor to evaluate individual scientists.

In the specific field of occupational health, the fact that more than half of the journals retrieved in the search are not indexed in SCI is a definite bias. This result would probably have been even worse if a less American dominated database - such as Embase-had been used. ${ }^{1}$ Furthermore, the impact factors of the few occupational health journals for which the impact factors exist are less than 2.119 (Environmental Health Perspectives) except for Critical Reviews in Toxicology (4.824) which is at the border end of occupational health. This can be compared with the mean impact factor of 
the other specialty journals retrieved in the search-that is, 1.938. This shows the low number of readers of occupational health journals, but also the delay between the publication of these journals and their indexation in Medline. In fact, this delay is short for the most well known journals (Lancet or New England fournal of Medicine) but may be up to 1 year for journals with a lower impact, such as many occupational journals. As the number of spontaneous readers of these journals is low, their articles will often be read only once they appear in bibliographic databases. Therefore, two factors must be added to the months of delay between publication and reading. Firstly, the actual time spent in writing the new article which will quote the occupational health journal. Secondly, the publication lag of this new article. The impact factor only takes into account the citation of an article within 2 years after its publication and this is therefore very unfavourable to the impact factor of many occupational health journals.

Last but not least, the fact that journal impact factors are not statistically representative of individual journal articles is even more accurate in the field of occupational health as an article dealing with occupational diseases which is published in a high impact factor journal will probably not be cited as much as the journal impact factor indicates. Use of the impact factor to select the journals which are to be followed up by the occupational health specialist or by the librarian is therefore not reliable. The occupational health research worker can use this tool, taking into consideration its limits and by bearing in mind the fact that publishing in a non-occupational health journal with a high impact factor may increase the possible number of readers but at the same time decrease the probability that his article will be read, and thus be cited, by the readers who are possibly interested.

A more quantitative method of selection of journals can be tested. Journals can be classified into four categories not based on their subject area, but on the number of articles they have published in the fields studied: $>100$ articles, 50-99, 10-49, and $<10$. The first three categories are presented in table 4 . The first two and the first three categories respectively represent $1.4 \%(n=8)$ and $6.6 \%(n=38)$ of journals and $27 \%$ and $52 \%$ of the published literature in the fields studied. This method seems to provide the best compromise between time and literature covered.

The list of journals presented in table 4 is accurate for the specific topics studied here, which cover important fields of occupational health. The method used may lead to the preclusion of articles dealing with other important topics of occupational health-such as occupational health services, occupational accidents, or evaluation of capacity to work. Nevertheless, the conclusions over the lack of reliability of the SCI in occupational health or the shortcomings of following up only occupational and environmental health journals would have been identical if all the aspects of occupational and environmental health had been covered.

Therefore, the method presented here can also be applied to study other aspects of occupational and environmental health subjects and to select the most interesting journals within more specific fields in occupational or environmental health.

The summaries of the journals and most of the abstracts are available free of charge on the internet, through the PubMed search system (http://www.ncbi.nlm.nih.gov/PubMed/). It provides access to the PubMed database of bibliographic information which is drawn primarily from Medline and PreMedline. It is possible to construct a search strategy for the summaries and abstracts of these eight or 38 journals, to run the strategy and to save the Uniform Resource Locator (URL) or address location-for example, bookmark. Reopening the URL will run the same strategy again.

We thank Mr R Medeiros for his valuable advice in editing the manuscript.

1 Gehanno JF, Paris C, Thirion B, et al. Assesment of bibliographic databases performance in information retrieval for occupational and environmental toxicology. Occup Environ Med 1998;55:562-6.

2 Garfield E. Citation analysis as a tool in journal evaluation. Science 1972;178:471-9.

3 Greenhalgh T. The Medline database. BMF 1997;315:1803.

4 Seglen PO. Why the impact factor of journals should not be used for evaluating research. BMf 1997;314:498-502.

5 Andersen H. ACTA sociologica på den internationale arena-hvad kan ssci fortælle? Dansk Sociologi 1996;2:72-8. (Cited in ref 4.)

6 Seglen PO. The skewness of science. Fournal of the American Society of Information Science 1992;43:228-38. 